\section{MUJERES EN CÍRCULO: ANÁLISE DO ATIVISMO VIRTUAL GERADO POR UMA COMUNIDADE FEMINISTA NO FACEBOOK}

\author{
Mujeres en Círculo: análisis del activismo virtual impulsado por \\ una comunidad feminista en Facebook \\ Mujeres en Círculo: analysis of the virtual activism ruled by a \\ feminist community on Facebook
}

\section{Deborah Rodriguez}

Licenciada em comunicação social pela Universidade da Havana, Cuba. Mestranda em estéticas e tecnologias da comunicação pelo Programa de Pós-Graduação em Comunicação da Universidade Federal Fluminense, Rio de Janeiro.

E-mail: debrs1990@gmail.com

RESUMO Este trabalho pretende analisar as práticas de ativismo virtual geradas no Facebook pela comunidade Mujeres en Círculo e tentar entender, a partir de uma aproximação etnográfica, de que maneira os discursos ali construídos contribuem para o empoderamento das mulheres dentro dos espaços sociais aos quais pertencem e como as narrativas patriarcais sobre gênero são subvertidas por meio dos debates ali gerados.

PALAVRAS-CHAVE Feminismo, Empoderamento, Redes sociais.

RESUMEN El presente trabajo pretende analizar las prácticas de activismo virtual impulsado en Facebook por la comunidad Mujeres en Círculo e intentar comprender, a partir de una aproximación etnográfica, de qué manera los discursos allí construidos contribuyen con el empoderamiento de las mujeres dentro de los espacios sociales a los que pertenecen y cómo los debates allí originados subvierten las narrativas patriarcales sobre género.

PALABRAS CLAVE Feminismo, Empoderamiento, Redes sociales.

ABSTRACT This article intends to analyze the practices of virtual activism ruled by the virtual community Mujeres en Círculo on Facebook, and understand, from an ethnographic perspective, how the discourses that their members construct help them to be more empowered within the social spaces to where they belong; and also, the way how patriarchal narratives about gender are subverted through the debates they engage in.

KEYWORDS Feminism, Empowerment, Social network sites. 


\section{INTRODUÇÃO}

Os sites de redes sociais (SRSs) têm tido, nas últimas décadas, presença importante na vida social de indivíduos e grupos. Por definição, esses espaços são entendidos como "a última geração de 'públicos mediados' - ambientes onde as pessoas podem se reunir publicamente através da mediação tecnológica” (Boyd, 2010, p. 2).

$\mathrm{Na}$ América Latina, estudos pioneiros sobre a temática da comunicação virtual propunham uma visão um tanto receosa em relação às mudanças éticas, morais e de apropriação das diversas ferramentas de sociabilidade que eram notáveis nesses ambientes (Sibilia, 2008). A utilização das redes como canais de desabafo, autoapresentação, construção social da individualidade e, com ela, exteriorização da intimidade provocou nos olhares acadêmicos certa apreensão quanto ao caos que poderia significar aquela "hiper-exteriorização" da vida privada em uma esfera, sem dúvidas, pública. O narcisismo e a performance, a simulação entre outros termos similares, começaram a aparecer nas produções acadêmicas do campo como resultado dessas inquietações no tocante àquilo que parecia ser o holocausto da autenticidade (Sibilia, 2008).

Por esse enfoque, a virtualidade e, especificamente, as redes sociais apresentavam-se como espaços fúteis de compartilhamento que possibilitavam aos usuários simular e criar identidades prêt-àporter (Sibilia, 2008). Para além dessas visões, alguns trabalhos mais contemporâneos têm reivindicado o espaço virtual como um terreno de trocas simbólicas efetivamente legítimas, assumindo a premissa de que cada manifestação da individualidade ali expressada é real, autêntica e contribui à constante atualização dos rasgos constitutivos da personalidade (Miller, 2011; Hine, 2000).

Seguindo essa linha de pensamento, o etnógrafo inglês Daniel Miller propõe que o Facebook - em particular - deveria ser entendido como um espaço de verdades intencionadas

[...] onde os sujeitos se mostrariam de modo mais "verdadeiro" do que off-line, partindo de três premissas: 1) o entendimento do Facebook como "verdade por intenção" - se as pessoas se sentem mais seguras para falar sobre elas mesmas em ambientes privados e elas o fazem no site, um lugar semipúblico, é porque elas realmente tinham a intenção de falar sobre ou expor algo; 2) a "habilidade tecnológica do site de revelar verdades não intencionais" [...]; e, principalmente, 3) o entendimento de "verdade por construção" - as pessoas despendem uma boa quantidade de tempo compondo seus próprios perfis no site, sendo essa "cuidadosa autoconstrução" [...] muito mais próxima da verdade de uma pessoa do que o que ela pode pertencer naturalmente desde seu nascimento. (Miller, 2011, p. 48)

Concordamos com esses apontamentos e optamos por entender as redes virtuais como fontes legitimas de autoapresentação e lugares onde o nível de exposição é regulado pelos sujeitos a partir de escolhas pessoais (Polivanov, 2014). Os usuários decidem que conteúdos publicar, onde, quando e quem pode visualizar suas postagens no Facebook, as quais, embora sejam manifestações performáticas, não deixam por isso de fazer parte da verdade pessoal que cada um quer "contar" em sua timeline. 
Em outras palavras, poderíamos dizer que a realidade, nos ambientes on-line, adota formas específicas pelas narrativas de si que os sujeitos constroem nesses ambientes e que constituem representações individuais e autorreflexivas (Giddens, 2002). Dessa maneira, o discurso virtual dos atores sociais tem de ser entendido como mais uma expressão da realidade vista através do prisma cognitivo, afetivo e contextual pelo qual esses sujeitos representam o mundo, si mesmos e sua relação com os outros, sua audiência imaginada (Boyd, 2010).

Estreitamente atrelada a essas questões, aparece a ideia da nova mídia, e especificamente as redes sociais, como espaço de ativismo considerável, onde indivíduos e grupos têm encontrado canal propício para desenvolver as mais diversas lutas. A respeito disso, Appadurai comenta:

[...] graças à mera multiplicidade de formas que assume [...] e à maneira rápida como se move no seio das rotinas da vida quotidiana, a comunicação eletrônica é uma ferramenta para que cada indivíduo se imagine como um projeto social em curso. (Appadurai, 1996, p. 14)

A partir do que o autor denomina "comunidades de sentimentos", nucleiam-se nesses ambientes on-line sujeitos unidos a partir de interesses comuns, dentre os quais escolhemos as lutas feministas como foco constitutivo da presente pesquisa.

Iremos discutir como o Facebook emergiu nos últimos tempos como uma ferramenta pela qual atuam movimentos de emancipação da mulher e feministas em geral. Para isso, analisaremos como corpus fundamental do trabalho o grupo temático Mujeres en Círculo: Seamos Cómplices.

Com um total de 375 membros ativos, o grupo foi criado em 2015 por uma ativista espanhola, não afiliada institucionalmente, residente no Brasil. Seu propósito, segundo ela, era:

Gerar um espaço de solidariedade e apoio entre mulheres, que desafiasse o doutrinamento patriarcal e acabasse com o mito de que sentimos inveja o tempo todo umas das outras e, portanto, constituímos rivais; estava sendo necessário para mim contar com um espaço dessa natureza no meu entorno de convivência, e por essas razões criei o grupo. ${ }^{1}$

Pretendemos, assim, analisar de que maneira os membros do grupo Mujeres en Círculo utilizam essa comunidade virtual como espaço de empoderamento e, ao mesmo tempo, mapear as principais questões que aparecem no centro do debate coletivo ali gerado e entender como elas funcionam como elemento aglutinador.

O levantamento dos dados foi feito durante dois meses por meio de entrevistas com os membros do grupo e por análise de conteúdo e observação participante. Lançou-se uma petição de colaboração no grupo, e os interessados em colaborar entraram em contato rapidamente, de maneira que, pela voluntariedade de algumas pessoas, conseguimos definir a amostra e levantar os dados de que precisávamos para encaminhar o trabalho, o qual foi feito tomando como principal inspiração as rotas metodológicas propostas pela etnografia.

1. Entrevista pessoal em janeiro de 2016 para a autora deste artigo. 


\section{FEMINISMO E REDES SOCIAIS: CASO MUJERES EN CÍRCULO}

A militância feminista atravessou vários momentos ao longo da história, tendo surgido enquanto movimento nos anos de pós-guerra, liderada em suas origens por mulheres da classe média europeia e dos centros urbanos dos Estados Unidos, fundamentalmente.

Em 1966, a ativista norte-americana Betty Friedan fundou uma das organizações icônicas do movimento: a National Organization for Women, conhecida como NOW. Mas só na década de 1970 os movimentos mais radicais da luta feminista começaram a emergir. Foi assim que nasceu o denominado "neofeminismo", assumindo posicionamento marcadamente contestatário e subversivo:

As intermináveis e acaloradas discussões sobre qual era a contradição ou o inimigo principal caracterizaram o desenvolvimento do neofeminismo não só nos Estados Unidos, mas também na Europa [...]. A lógica dos debates tem sido a mesma: enquanto as mais feministas buscar convencer os políticos de que a opressão das mulheres não é somente uma simples consequência do Sistema, mas um sistema especifico de dominação no qual a mulher é definida nos termos do homem, os políticos não conseguiam deixar de ver os homens como vítimas do sistema e de enfatizar que não se devia enfrentá-los. (De Miguel, 2011, p. 3)

Sob o lema "O pessoal é político", as feministas mais radicais iniciaram lutas por equidade de gênero e oportunidades sociais baseadas nas capacidades físicas e intelectuais das pessoas, e não em seu sexo-elemento que se tornou seu eixo político fundamental. Entre várias tentativas de revolucionar a ordem existente, em que a mulher estava socialmente em desvantagem, criaram-se centros educativos para espalhar o discurso antipatriarcal dominante na sociedade norte-americana, espaços de autoajuda para mulheres que tivessem sofrido algum tipo de violência como consequência da subordinação ao homem. Porém, para além da força do movimento desde os primeiros anos e a popularidade que progressivamente foi alcançando, as maneiras de abordar as preocupações a respeito do patriarcado estiveram influenciadas, entre outras razões, pelas condições de acesso e o nível de visibilidade que as tecnologias de difusão põem à disposição de causas sociais - no caso, o feminismo -, e também pelas correntes de pensamento e enfoques de luta que têm se desenvolvido em contextos sócio-históricos diversos.

Segundo a acadêmica norte-americana Joan Scott, o feminismo como movimento global aborda as preocupações essenciais em relação ao gênero basicamente a partir de três posturas:

A primeira, um esforço inteiramente feminista que tenta explicar as origens do patriarcado. A segunda situa-se no seio de uma tradição marxista e procura um acordo com as críticas feministas. A terceira, fundamentalmente dividida entre o pós-estruturalismo francês e as teorias anglo-americanas de relações de objeto, inspira-se nas várias escolas de psicanálise para explicar a produção e a reprodução da identidade de gênero do sujeito. (Scott, 1989, p. 9)

Para além do reconhecimento histórico feito por Scott (1989), é importante ressaltar o papel que muitos movimentos alternativos à militância feminista desempenham e como essas três posturas inserem- 
se em seus discursos. Ao dizer isso estamos nos referindo àquelas agrupações que, sem deixar de ser partícipes de lutas pela equidade de gêneros, não praticam uma afiliação formal a partidos ou organizações com objetivos políticos e de mobilização coletiva definidos. Esse tipo de feminismo não afiliado, porém, tem alcançado, nos anos recentes, voz importante na esfera pública internacional, ocupando essencialmente espaços de compartilhamento social através da virtualidade para espalhar suas ideias. Conceitualmente, o ciberativismo pode ser entendido como:

[...] toda estratégia que persegue a mudança da agenda pública, a inclusão de um novo tema na ordem do dia da grande discussão social, mediante a difusão de determinada mensagem e sua propagação através do "boca a boca" multiplicado pelos meios de comunicação e publicação eletrônica pessoal. (Ugarte, apud Reis; Alves; Loureiro, 2013, p. 6)

Desse modo, pela sua capacidade de "globalizar" conteúdos e temáticas que poderiam ser consideradas de interesse local, as redes são o principal canal através do qual muitos movimentos sociais, e não só o feminismo, têm emergido e se consolidado, facilitando o uso de ferramentas de socialização virtual em prol do ativismo sociopolítico não formalmente engajado, um dos tópicos que iremos discutir neste trabalho.

\section{O PESSOAL É POLITICO E, EM TEMPOS DE FACEBOOK, TAMBÉM PÚBLICO}

Em outubro de 2015, usuários ativos nas redes sociais foram partícipes da mobilização massiva gerada pela campanha \#meuamigosecreto no Facebook e no Twitter, hoje conhecida como a "Primavera das Mulheres", em que usuários de sites de redes sociais do mundo inteiro valeramse da hashtag para denunciar comportamentos machistas - de amigos, conhecidos, pessoas próximas a eles -, em ambientes de lazer, estudo ou trabalho, que os afetavam física ou psicologicamente. Alguns exemplos:

\#meuamigosecreto acha que homem pode ser barrigudo, feio, largado. Mulher, se não for toda bonitona e gostosa, tem mais é que ficar sozinha.

\#meuamigosecreto é abusivo com a esposa, mas na ausência dela não sabe nem fritar um ovo.

\#meuamigosecreto paga de defensor da igualdade nas redes sociais, mas humilha mulher nos grupinhos de whatsapp

\#meuamigosecreto na época da faculdade afirmou que para mulher bonita é fácil tirar A nas disciplinas, principalmente se o professor fosse homem.

\#meuamigosecreto taxa mulher de doida e manda fazer terapia quando ela acorda se sentindo um pouco pra baixo

A campanha surgiu como iniciativa da feminista brasileira Juliana Faria ${ }^{2}$ com o propósito de encorajar mulheres a denunciar assédios que

2. Ativista brasileira e representante do grupo Think Olga, projeto coletivo on-line que tem como objetivo "criar um olhar investigativo sobre o universo feminino contemporâneo". Mais informações disponíveis em: http://bit.ly/2eU4rb8. 
tivessem sofrido como consequência do machismo, e o que começou como uma manifestação local aos poucos foi alcançando dimensões globais, espalhando-se pelas timelines de mulheres do mundo inteiro e, finalmente, tomando as ruas.

Esse exemplo mostra a capacidade dos sites de redes sociais para potenciar o ativismo político na defesa das causas mais diversas. 0 feminismo como movimento social tem encontrado na virtualidade ambiente propício para gerar lutas que não só denunciam, mas que também contribuem para a unificação do movimento e para que as ideias que defendem consigam atingir a maior quantidade de mulheres possível:

O uso da internet, apesar dos seus limites e das repressões, possibilita uma forma mais democrática de retratar e divulgar as ideias feministas, viabilizando uma produção estética bastante ampla e inúmeros debates sobre as ideias difundidas, já que para cada postagem abre-se a possibilidade de comentários para o público receptor. (Ferreira, 2013, p. 38)

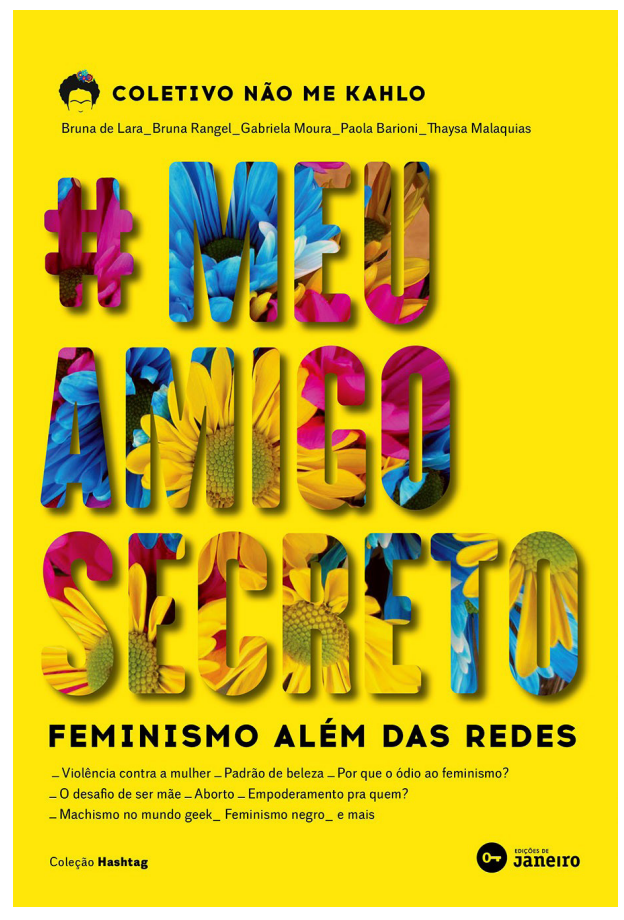

Figura 1. Capa do livro \#MeuAmigoScreto, produzido pelo coletivo Não Me Kahlo.

No Brasil, a página do Facebook chamada Não Me Kahlo ${ }^{3}$ foi fundamental na viralização da campanha \#meuamigosecreto, tanto que seus administradores anunciaram recentemente a disponibilização de um livro editado por eles mesmos, onde compilaram os desabafos mais significativos. 0 editorial que anunciava o livro era o seguinte:

Primeiro título da Coleção Hashtag - que explora temas de relevância coletiva repercutidos na internet - \#MeuAmigoSecreto:

3. O nome faz referência a Frida Kahlo, pintora e ativista mexicana, exemplo e guia de muitos movimentos feministas na América Latina. 
feminismo além das redes dá continuidade aos debates do mundo virtual e reúne artigos inéditos das cinco integrantes do coletivo Não Me Kahlo, todos ligados por um objetivo em comum: a desconstrução do machismo. O livro apresenta um material consistente de pesquisas que servem de apoio aos que se interessam em compreender melhor as raízes do machismo e quais são as pautas feministas: padrão de beleza, violência contra a mulher, aborto, o desafio de ser mãe, machismo no mundo geek, feminismo negro e o porquê do ódio ao feminismo são alguns dos temas no livro que tem prefácio da filósofa Djamila Ribeiro. ${ }^{4}$

O Facebook em particular, por ser uma das redes mais populares e com maiores índices de acesso no ciberespaço, ${ }^{5}$ é tido como um canal favorável para potenciar a visibilidade de temáticas que, aos olhos do movimento feminista global, têm sido quase silenciadas na agenda pública das mídias tradicionais. Desse modo, perfis e timelines em grupos virtuais servem também como canais alternativos para dar voz a temáticas prioritárias para a causa e nuclear afetos e sensibilidades coletivas entre as pessoas afetadas e envolvidas nesses debates.

Ao abordar essas questões, não podemos desconhecer que existe no seio do movimento feminista contemporâneo uma preocupação: o estereótipo da mulher politicamente ativa como feminazi, ${ }^{6}$ que promulga ódio aos homens e renúncia à feminidade como principais vias para contestar o sistema heteronormativo e falocêntrico. A imagem da mulher chata e muitas vezes "rude" demais, que ataca o homem sem razões aparentes, é, sem dúvidas, o estereótipo dominante quando se ouve falar sobre uma militante feminista, e esse discurso clichê tornouse alimento para piadas e brincadeiras que também aparecem com muita frequência nos sites de redes sociais.

Algumas páginas e grupos temáticos estão sendo criados para fazer frente a esses discursos, como é o caso da comunidade Mujeres en Círculo, objeto da nossa análise. Tendo em consideração que o discurso torna-se o dispositivo pelo qual a identidade de gênero se constitui e, ao mesmo tempo, constitui a materialização da resistência por meio da linguagem (Butler, 2002), o papel da ocupação de alguns espaços virtuais para espalhar a mensagem feminista é realmente significativo, como veremos adiante.

\section{DISCURSOS DE PODER E RESISTÊNCIA NOS SITES DE REDES SOCIAIS}

Foucault (1988) discute a questão da repressão das denominadas "outras" sexualidades como uma consequência do controle político das elites dominantes, o que, segundo o próprio autor, só pode ser subvertido por meio de resistência discursiva:

Se a repressão foi, desde a época clássica, o modo fundamental de ligação entre poder, saber e sexualidade, só se pode liberar a um preço considerável: seria necessário nada menos que uma

4. Retirado de https://www.facebook.com/NaoKahlo/.

5. Mais dados disponíveis em: http://www.alexa.com/topsites.

6. Termo pejorativo usado para se referir a mulheres que lutam por igualdade de gênero. 
transgressão das leis, uma suspensão das interdições, uma irrupção da palavra. (Foucault, 1988, p. 11)

Cada vez mais, as pessoas usam as redes como espaços de empoderamento e liberdade de expressão, uma espécie de via para expor sua intimidade como forma de buscar apoio coletivo em momentos de fragilidade, e isso está sendo feito não apenas em comunidades temáticas - os perfis pessoais de cada um são um reflexo claro.

Exemplo disso é a seguinte postagem, de janeiro de 2016, em um grupo temático sobre estética e beleza, em que uma usuária declarou abertamente ter se sentido agredida por seu namorado ao consultar com ele sobre uma possível mudança de cor de cabelo:

Tô desistindo de ficar ruiva laranjinha, meu namorado tá falando "você não é branquinha" "vai ficar feio" "vai acabar com o seu cabelo" ai gente, to desistindo..........

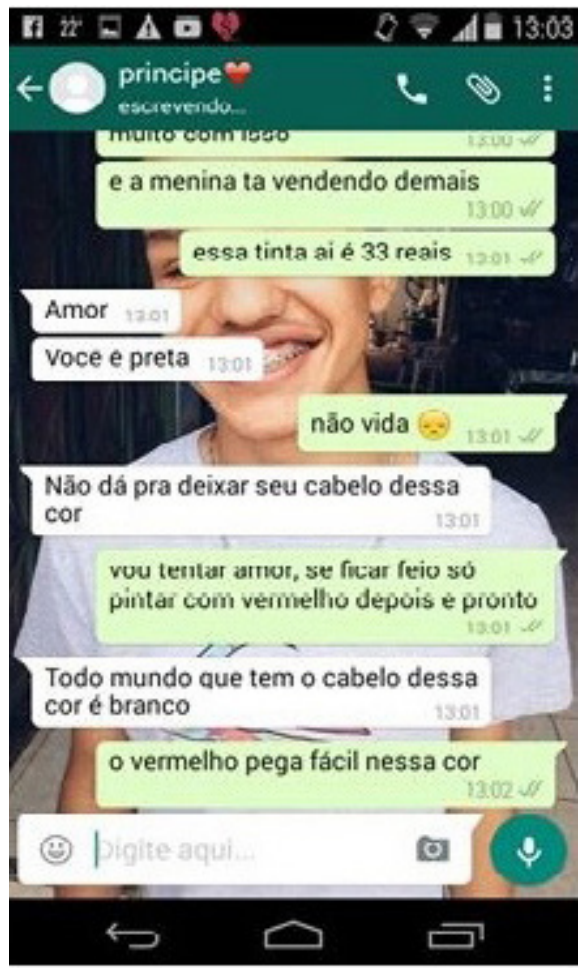

Figura 2. Postagem feita por usuária em comunidade virtual do Facebook.

Após ser publicada, a usuária começou a receber comentários de apoio dentro do próprio grupo que encaravam como agressivo o conteúdo que a tinha magoado; essas mensagens de apoio expressavam como linha de pensamento fundamental a reivindicação da mulher como objeto de violência psicológica por parte do homem. Neste trabalho, porém, não iremos discutir os perfis pessoais, mas tentaremos mapear como se dão as relações entre tecnologia e resistência feminina nas comunidades e grupos do Facebook e iremos, para tanto, analisar um caso particular.

Mujeres em Círculo é a tentativa de um grupo de mulheres de diversas regiões do mundo de habilitar um espaço de debate e suporte coletivo quando alguma delas encontra-se em situações de 
vulnerabilidade geradas por atos de violência psicológica, acossamento ou, simplesmente, sente a necessidade de expressar algum tipo de inconformidade em relação ao sistema patriarcal em realidades sociopolíticas e geográficas distintas; é também uma maneira de se conectar com mulheres do mundo inteiro através dos afetos que ali se constroem. Com enfoque essencialmente inclusivo, as políticas de privacidade do grupo permitem a cada membro adicionar não só mulheres que pertençam a suas redes de contatos, mas também aquelas pessoas que, em sua condição de transgênero ou transexual, sintam vontade de participar.

No grupo, observamos que as discussões são utilizadas para burlar a repressão discursiva em torno da sexualidade e dos padrões de comportamento feminino socialmente aceitos. A normalização (Foucault, 1988) torna-se o principal objeto da subversão no marco das polêmicas geradas em Mujeres em Círculo, partindo da abordagem de temáticas como identidade de gênero, sexualidade, estética de livre escolha, machismo, violência psicológica atrelada a relacionamentos amorosos abusivos, e de situações como gravidez e parto, entre muitas outras preocupações que, diariamente, são compartilhadas pelos membros do grupo em prol do debate e suporte coletivo.

Muitas das conversas aligeradas expressam a vontade de desconstruir a clássica noção do feminismo dos primórdios que concebia o gênero como interpretação cultural do sexo (Butler, 2003). Diariamente são discutidas, entre outros assuntos, a livre escolha da mulher em matéria de identidade de gênero e a desconstrução do estereótipo estético da mulher feminista. No marco da comunidade virtual aqui analisada, apreciamos a recorrência de debates teóricos que, sem serem rigorosos demais em suas abordagens, têm como propósito "mexer em ideias enraizadas na cabeça de muitas mulheres que são um reflexo do doutrinamento patriarcal ao qual somos submetidas desde crianças e das visões biologicistas do gênero como um destino e não como uma escolha”, segundo D., membro ativa do grupo, em entrevista pessoal.

Entrar em contato com outras visões sobre o que significa ser mulher na contemporaneidade para além das restrições físicas, legislativas e culturais é uma das vantagens que os membros da comunidade reconhecem nela.

Gênero passa a ser uma forma de denotar as "construções culturais", a criação totalmente social de ideias sobre os papéis apropriados para mulheres e homens. Constitui uma forma de se referir às origens exclusivamente sociais das identidades subjetivas de homens e mulheres. Gênero é, segundo essa definição, uma categoria social imposta sobre um corpo sexuado. (Scott, 1989, p. 4)

P., criadora do grupo, em entrevista pessoal, afirma que:

Ao ser um grupo que une mulheres queridas ao redor de outras mulheres queridas, o ambiente vai tornando-se um espaço íntimo no qual temos a possibilidade de revelar nossas emoções, encontrar apoio em semelhantes e aprender do que pode aportar cada um.

Por sua parte, G., outra usuária que compõe a comunidade, referese ao impacto que tem tido na sua vida pessoal o pertencimento a uma congregação dessa natureza: 
Não importa se somos chinesas, brasileiras ou espanholas, as injustiças são as mesmas, existem uns padrões e experiências que pelo simples fato de sermos mulheres se repetem em todo o mundo. A possibilidade de ter um espaço onde desabafar ou procurar ajuda ou informação em relação a determinados temas é uma ferramenta muito útil que nos empodera e nos impulsa. Pessoalmente utilizo o grupo para compartilhar experiências e desabafar, também para compartilhar informação caso alguma outra menina esteja atravessando pela mesma situação que eu, ela tem que saber que não está sozinha.

Na fala de G., apreciamos que o grupo significa para ela um espaço de solidariedade feminina, como pudemos constatar pela análise de postagens como as que aparecem abaixo:

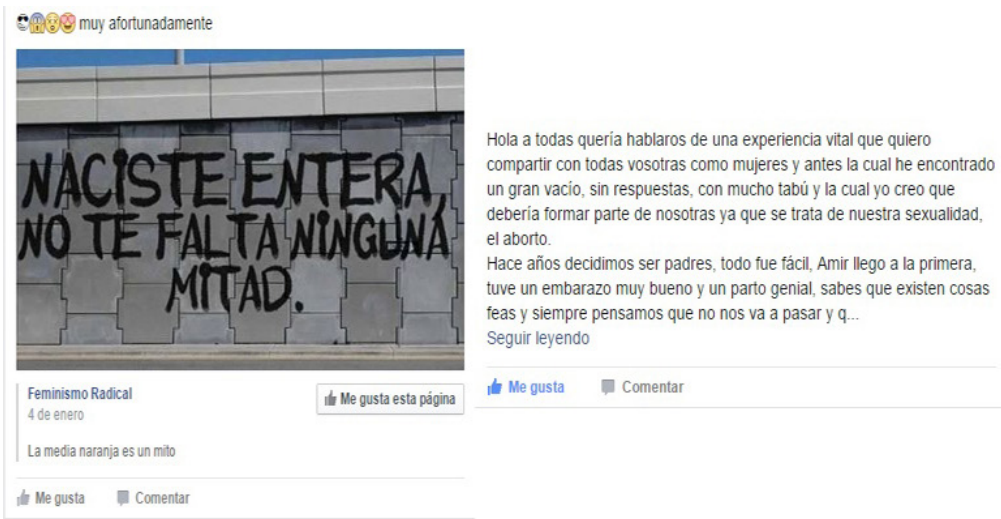

Figura 3. Postagens realizadas por alguns membros da comunidade Mujeres en Círculo

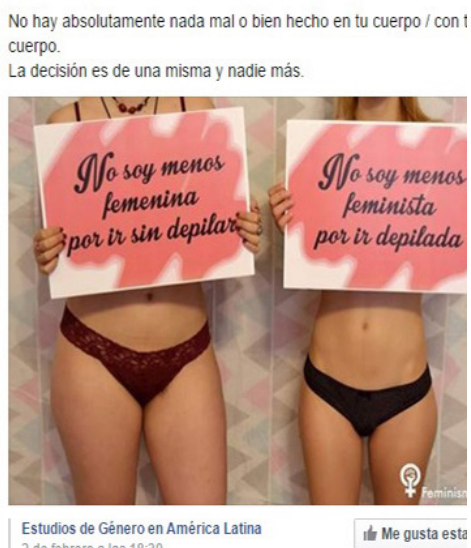

Nessas postagens, observamos que a comunidade serve, em muitos casos, como uma espece de "reunião de amigas", onde a fragilidade de cada uma é exposta por meio de relatos íntimos, constituindo-se assim em atos de alto nível de sociabilidade (Joinson, 2005). A esse respeito, G. declara como se sentiu depois de ter feito uma postagem no grupo, procurando apoio, com um relato íntimo sobre um sucesso recente em sua vida privada: "Não errei ao pensar nas mensagens que receberia tanto no grupo quanto por privado, cada uma tem sua história, foi como um abraço para a alma, não me sentia mais sozinha, senti a força de todas as mulheres que me impulsionaram a seguir”.

Sobre esse particular, Joinson aponta que, na comunicação estabelecida entre os sujeitos através da Internet, "as pessoas sentemse mais à vontade para se abrir em comparação com os equivalentes off-line, e muito desse processo de self-disclosure é bem mais cândido" (Joinson, 2005, p. 25). Vemos, assim, que os membros do grupo Mujeres en Círculo conseguem usar a comunidade virtual com o propósito de falar sobre temas que poderiam parecer "íntimos demais" para serem discutidos em ambientes públicos como as redes sociais; porém o leque de temáticas ali abordadas mostra que, apesar de muitos usuários do grupo sequer se conhecerem extravirtualmente, isso não constitui impedimento para que o processo de self-disclosure tenha lugar. Assim, de acordo com Baym (2012), os contatos do grupo passam a ser reconhecidos pelos usuários como pessoas confiáveis com as quais podem se sentir à vontade para partilhar experiências íntimas por meio 
de desabafos, e isso passa, sem dúvidas, por critérios de legitimidade, como a credibilidade das pessoas que fazem parte da rede.

Cria-se, assim, relação de confiabilidade indireta entre os membros do grupo, que acontece a partir da transferência de capital social (Recuero, 2005), isto é, quando os integrantes são capazes de imaginar que os outros membros possuem inclinações -intelectuais e políticas neste caso - similares à de pessoas, também do grupo, que conhecem com maior intimidade. No entanto, para além da visível intimidade construída no interior da comunidade, é importante demarcar que esses atos refletem importantes traços de autorreflexividade (Giddens, 2002) e que cada expressão do eu que se manifesta na comunidade constitui, portanto, uma performance de si (Polivanov, 2014). Traços da própria personalidade, vivências e critérios são selecionados pelos membros do grupo para serem visibilizados e debatidos, e tudo isso - especialmente assuntos mais sensíveis - é cuidadosamente construído na virtualidade.

Da mesma maneira, temos notado que no grupo existe uma linha constante de discussão sobre temáticas referidas ao corpo da mulher como objeto de desejo e manipulação: a vergonha estética a que muitas mulheres são expostas no seu dia a dia pelo seu físico; a maternidade como um destino, e não tanto quanto uma escolha pessoal; e o machismo dominante no desenvolvimento de métodos anticoncepcionais que sometem o corpo da mulher a procedimentos altamente invasivos e colocam nela a responsabilidade da proteção sexual, como vemos na seguinte postagem:

\section{As vezes não paramos para pensar nestas coisas ::}

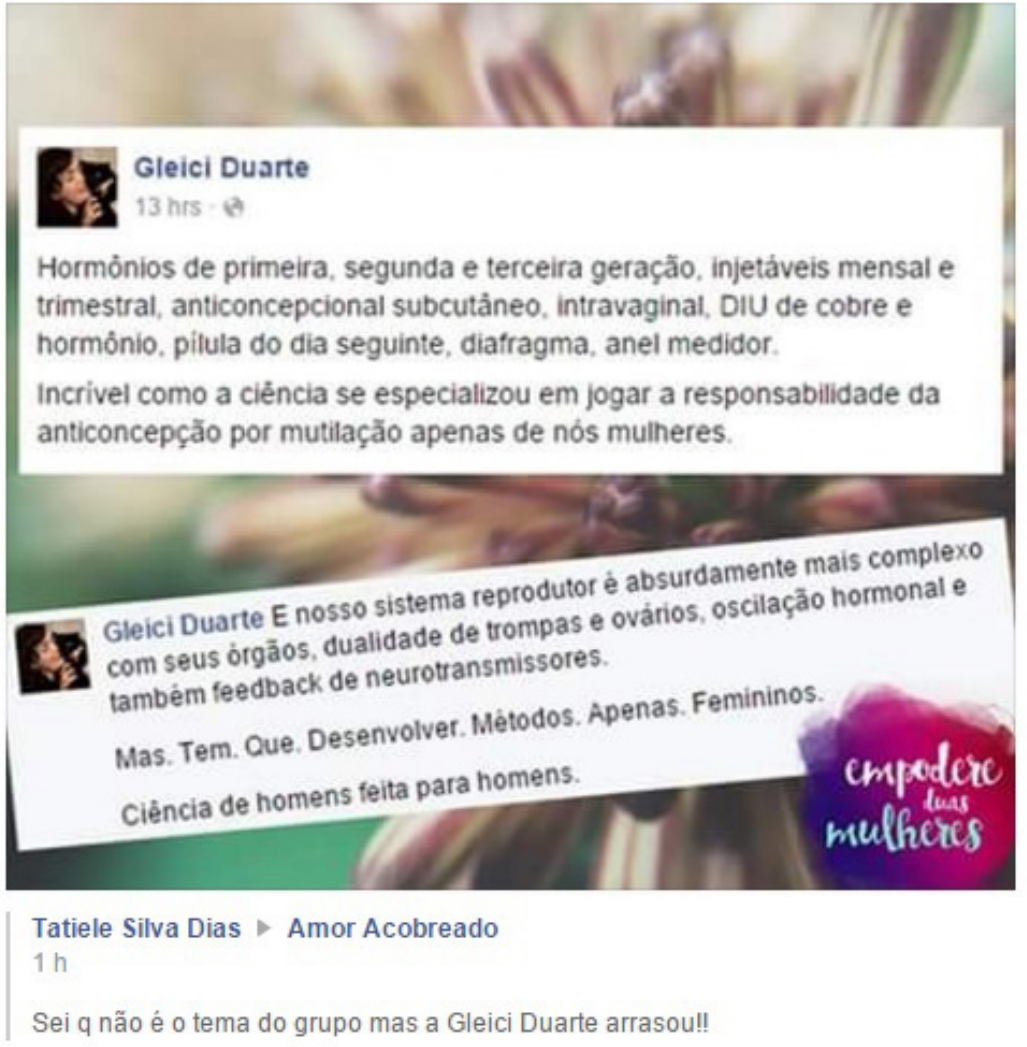

Figura 4. Postagem realizada por usuária do grupo Mujeres en Círculo. 
As temáticas anteriormente mencionadas predominam no debate do grupo, havendo alguns assuntos que muitas vezes parecem ser deixados de lado pela grande mídia. Foucault (1988) aponta a natureza sistêmica do dispositivo da sexualidade, suas interconexões e ligações a fatores de índole cultural, educativa e de resistência que estão sempre sendo atravessados por relações de poder dadas, em que o ato de se atrever a "falar" sobre temáticas não prioritárias na agenda do sistema no qual estão inscritas significa o primeiro passo para fazer frente à dominação:

A sexualidade é o nome que se pode dar a um dispositivo histórico: não a realidade subterrânea que se aprende com dificuldade, mas a grande rede da superfície em que a estimulação dos corpos, a intensificação dos prazeres, a incitação ao discurso, a formação dos conhecimentos, o reforço dos controles e das resistências encadeiamse uns aos outros, segundo algumas grandes estratégias de saber e de poder. (Foucault, 1988, p. 100)

No caso que estamos tentando mapear, os atos de resistência através da virtualidade e a disposição de "falar" sobre certos assuntos e preocupações são um propósito explícito e uma das finalidades essenciais da comunidade Mujeres en Círculo. Dar voz e visibilidade a temas considerados "tabu" no entorno do mainstream, fazer resistência aos discursos conservadores a respeito do corpo feminino e dos comportamentos que se esperam da mulher, e particularmente da mulher ocidental, construir laços de sociabilidade e solidariedade e contestar os dispositivos de dominação patriarcais pelo uso de ferramentas tecnológicas são alguns dos fins essenciais do grupo.

Se é certo que a tecnologia não é por si só capaz de impulsionar mudanças, o fato de se apropriar desses suportes, e dos próprios dispositivos que servem à opressão para revertê-la, faz uma diferença considerável. Mujeres en Círculo representa uma ferramenta de luta para as mulheres que nessa comunidade coabitam, sendo o discurso a principal materialização desses embates entre as tentativas de dominação cultural que ainda existem nas nossas sociedades e as subalternidades que a elas enfrentam-se.

\section{CONCLUSÕES}

Sociabilidade "diz respeito ao estabelecimento de laços sociais entre os atores, sem que haja a determinação de um conteúdo para tal fim. A relação estabelecida entre eles é o próprio fim da relação" (Polivanov, 2014, p. 155).

No grupo Mujeres en Círculo vimos como esses laços são construídos e fortalecidos em cada uma das postagens e as ações de valor que elas promovem (curtidas, comentários etc.). Os conteúdos publicados na comunidade analisada refletem a necessidade de muitas mulheres de reconhecer a existência de um entorno onde expressar suas inconformidades quanto às logicas patriarcais dominantes. Conforme nos diz F., membro do grupo:

O grupo nos permite ganhar muito mais conforto e confiança na hora de expressar nossos sentimentos [...] na verdade eu não sei se quero poder, só preciso saber que posso contar com um espaço de 
liberdade de expressão, tanto quanto se estivesse tomando um café com amigas e conversando.

Cabe assim dizer que as novas resistências canalizadas através das redes sociais estão nos convidando a entender a questão das lutas feministas sob novos enfoques, pela perspectiva das reconfigurações a nível de formato, conteúdo e abordagem que são visíveis no dia a dia para quem acompanha e convive nesses espaços. $O$ anonimato das redes, sua capacidade de agrupamento e o aprimoramento de suas funcionalidades em prol da especialização de alguns ambientes para o debate têm feito do Facebook um espaço ideal para o desabafo e a expressão de inconformidades por parte de mulheres que convivem em localidades onde o machismo afeta seu desenvolvimento social e emocional.

Mujeres em Círculo, por ter enfoque inclusivo e participativo, promove polêmicas que, sem promulgar o ódio aos homens - como têm sido lidas algumas das tendências discursivas dentro do feminismo radical -, oferecem outra visão das problemáticas de gênero na sociedade ocidental contemporânea. Sem ter o propósito político definido de transcender o entorno virtual e tomar as ruas, a maior conquista do grupo reside em sua capacidade de empoderar mulheres e educá-las quanto ao reconhecimento de atitudes machistas, que muitas vezes elas mesmas reproduzem sem ter muita consciência do que seus comportamentos significam.

Segundo P., sua criadora, em entrevista pessoal, o grupo tem conseguido que muitas mulheres se sintam donas do próprio corpo e espiritualidade, tendo como principal ganho conquistar

[...] por um lado o apoio de outras que se reconhecem nas tuas vivências, por outro a possibilidade de avançar até outra emoção: o orgulho de não ser uma vítima do sistema patriarcal, mas uma peça do mesmo e, como tal, um sujeito com a capacidade de mudar certo tipo de ordens e situações.

Ainda que em pequena escala, as postagens e trocas de opiniões que ocorrem no marco do grupo, e são igualmente partilhadas por outras comunidades afins dentro do Facebook, estão introduzindo algumas mudanças interessantes no campo das lutas políticas pelos direitos das mulheres nas sociedades ocidentais a que elas pertencem. O uso da ferramenta virtual em prol do ciberativismo permite aos membros de Mujeres en Círculo, e particularmente às mais ativas em matéria de publicações, alcançar um número considerável de mulheres que talvez não fossem tão politicamente ativas nessas temáticas, às vezes por falta de acesso a fontes de informação, mas que são ativas na virtualidade, e isso constitui uma oportunidade para chegar nesse público potencial. Aplicando a estratégia da bola de neve, as mulheres que fazem parte do grupo vão espalhando a mensagem feminista e publicizando sua existência em seus perfis pessoais com o propósito de alcançar mulheres e pessoas de sua própria rede de contatos interessadas em participar das discussões que ali acontecem. É importante reforçar que o grupo não transcende a virtualidade, sua tarefa educativa limita-se a propor temáticas que afetam o universo feminino e devem ser pensadas e discutidas visando empoderar esses grupos em nível social.

Assim, o desafio principal desta pesquisa foi tentar entender, a partir de uma aproximação de inspiração etnográfica, como essas ações 
de valor virtuais que ali se desenvolvem dinamizam a vida social das mulheres que participam, seja em condição de emissoras de conteúdo ou leitoras. Falar de seus próprios corpos e das inconformidades que sente em relação a eles, problematizar a ideia de que a maternidade pode ser uma escolha, e não uma missão vital, e aprender a reconhecer expressões de machismo até em si mesmas e combatê-las são alguns elementos que, no nível do discurso, evidenciam que o grupo funciona para essas mulheres como um espaço de crescimento político, social e educativo, constituindo assim a tecnologia um importante veículo para espalhar a mensagem feminista e fortalecer, em nível micro, mas não por isso menos importante, o papel social da mulher.

\section{REFERÊNCIAS}

APPADURAI, A. Dimensões culturais da globalização. Lisboa: Teorema, 1996.

BAYM, N. Fans or friends?: seeing social media audiences as musicians do. Participations: Journal of Audience and Reception Studies, v. 9, n. 2, nov. 2012, p. 286-316.

BOYD, D. Social network sites as networked publics: affordances, dynamics, and implications. In: PAPACHARISSI, Z. (Ed.). A networked self: identity, community, and culture on social network sites. Londres: Routledge, 2010.

BUTLER, J. Problemas de gênero: feminismo e subversão da identidade. Rio de Janeiro: Civilização Brasileira, 2003.

York: Paidós, 2002

Cuerpos que importan: sobre los límites materiales y discursivos del sexo. Nova

DE MIGUEL, A. Neofeminismo: los años sesenta y setenta. In: Los feminismos a través de la historia. Madrid: 2011. Disponível em: http://bit.ly/2edJwzi. Acesso em: 2 nov. 2016.

FERREIRA, G. S. Feminismo e redes sociais na Marcha das Vadias no Brasil. Revista Ártemis, v. 15, 2013.

FOUCAULT, M. História da sexualidade I: a vontade de saber. Rio de Janeiro: Gallimard, 1988.

GIDDENS, A. Modernidade e identidade. Rio de Janeiro: Jorge Zahar, 2002.

HINE, C. Etnografía virtual. Cidade do México: Editorial UOC, 2000

JAGUARIBE, B. Modernidade cultural e estéticas do realismo. ECo-Pós, v. 9, n. 1, jan.-jul. 2006, p. 222-243.

JOINSON, A. Internet behaviour and the design of virtual methods. In: HINE, C. Virtual methods: issues in social research on the Internet. Nova York: Berg, 2005.

MILLER, D. Tales from Facebook. Londres: Polity Press, 2011.

POLIVANOV, B. Dinâmicas identitárias em sites de redes sociais: estudo com participantes de cenas de música eletrônica no Facebook. Rio de Janeiro: Luminária Acadêmica, 2014.

PRECIADO, B. Manifesto contrassexual: práticas subversivas da identidade sexual. São Paulo: Opera Prima, 2004

RECUERO, R. Um estudo do capital social gerado a partir de redes sociais no Orkut e nos weblogs. In: COMPÓS, 2005. Anais. Porto Alegre: Universidade Federal do Rio Grande do Sul, 2005

REIS, L. T.; ALVES, E. E. M. S.; LOUREIRO, C. Ativismo de Sofá: O movimento feminista no Facebook. In: INTERCOM, 15, 12-14 jun. 2013. Mossoró-RN. Anais. Mossoró: Sociedade Brasileira de Estudos Interdisciplinares da Comunicação, 2013.

RODRIGUES, L. M.; LUVIZOTTO, C. K. Feminismo na internet: o caso do coletivo marcha das vadias e sua página no Facebook. Colloquium Humanarum, v. 11, n. especial, p. 367-375, 2014. Disponível em: http://bit.ly/2edKDPu. Acesso em: 2 nov. 2016. 
ROLNIK, S. Toxicômanos de identidade: subjetividade em tempos de globalização. In: LINS, D. (Org.). Cultura e subjetividade: saberes nômades. Campinas: Papirus, 1997.

SCOTT, J. Gender: a useful category of historical analyses. Nova York: Columbia University Press, 1989

SIBILIA, P. O show do eu: a intimidade como espetáculo. Rio de Janeiro: Nova Fronteira, 2008. 